\title{
Prevalence and cesarean rates of immigrant adolescent pregnancies
}

\author{
Ozer Birge $^{1}$, Aliye Nigar Serin ${ }^{2 *}$, Ilkan Kayar ${ }^{3}$
}

\author{
${ }^{1}$ Department of Obstetrics and Gynecology, Faculty of Medicine, Akdeniz University, Antalya, Turkey \\ ${ }^{2}$ Department of Obstetrics and Gynecology, Faculty of Medicine, Karamanoğlu Mehmetbey University, Karaman, \\ Turkey \\ ${ }^{3}$ Department of Obstetrics and Gynecology, Osmaniye State Hospital, Osmaniye, Turkey
}

Received: 09 January 2021

Accepted: 10 February 2021

\section{*Correspondence:}

Dr. Aliye Nigar Serin,

E-mail: nserin85@hotmail.com

Copyright: (C) the author(s), publisher and licensee Medip Academy. This is an open-access article distributed under the terms of the Creative Commons Attribution Non-Commercial License, which permits unrestricted non-commercial use, distribution, and reproduction in any medium, provided the original work is properly cited.

\begin{abstract}
Background: aim of this study was to compare Syrian migrant adolescent pregnancies and Turkish adolescent pregnancies, who gave birth in Osmaniye State Hospital.

Methods: 22,724 women who gave birth at the Osmaniye State Hospital obstetrics and gynecology department between January 2013 and January 2020 were screened retrospectively. 868 Turkish adolescent pregnant women and 522 Syrian migrant adolescent pregnant women were compared. Whether the differences between Turkish and Syrian adolescents were noteworthy (95\% confidence interval) was determined using the independent samples test and Pearson Chi-Square test with statistical software Minitab (version 16.0, USA).

Results: A total of 22,724 births, including 15,883 Turkish and 6841 Syrian immigrants, were analyzed. The number of Turkish adolescent pregnant women was $868(5.5 \%)$, the number of Syrian adolescent pregnant women was 522 (7.6\%), the rate of Syrian adolescent pregnancy was higher. The cesarean rate was observed $36.7 \%$ in Turkish adolescent pregnancies and $20.1 \%$ in Syrian adolescent pregnants, cesarean rates were significantly higher in Turkish adolescent pregnants $(\mathrm{p}<0.001)$. When the total of $1390(6.1 \%)$ adolescent pregnancies were evaluated in Osmaniye, where there were intense migrants and Syrian camp, the cesarean rate was found to be $30.5 \%$, and the birth rate of low birth weight below 2500 gm was $11.1 \%$.

Conclusions: Maternal and fetal complications increase in adolescent pregnancies. War and migration are associated with poor obstetric outcomes in pregnancies. With Syrian immigration, an increase in adolescent pregnancy rate, cesarean rate, and low birth weight rate was observed in the region. For these reasons, studies should be done to prevent Syrian adolescent pregnancies. Social and education support, regular follow-up should be done to improve pregnancy outcomes. Adolescent pregnant women are more likely to have vaginal delivery. Therefore, normal vaginal delivery should be followed unless there is an emergency cesarean indication.
\end{abstract}

Keywords: Adolescent pregnancy, Cesarean section, Syrian pregnancy

\section{INTRODUCTION}

The adolescent period describes the transition period from childhood to adulthood with psychological and social changes. The World Health Organization (WHO) defines the adolescent period between the ages of 10-19. ${ }^{1}$ Adolescent pregnancy is considered a common social problem with serious effects on maternal and child health, especially in developing countries. ${ }^{2}$ It is estimated that $11 \%$ of births in the world are adolescent pregnancies and more than $90 \%$ of these pregnancies are in middle-low income countries. ${ }^{3} 2013$ Turkish Demographic and Health Survey (TDHS-2013) data showed that adolescents frequency is $17.2 \%$ of the Turkish population and adolescent pregnancy rate is $4.6 \% .^{4}$

Adolescent pregnancies are among high-risk pregnancies and associated with poor maternal and fetal outcomes. ${ }^{5}$ In adolescents, pregnancy-induced hypertension (PIH), 
anemia, postpartum hemorrhage, low weight gain during pregnancy, preterm delivery, low birth weight infant, and an increase in perinatal mortality are observed. ${ }^{6,7}$

As in Turkey all over the world, adolescent pregnancy age is affected by low socio-cultural level and different ethnic backgrounds. Adolescent pregnancy rates in Spanish and black people in America are higher than other ethnic groups. ${ }^{8}$ Similarly, the adolescent pregnancy rate is increasing due to low socio-cultural levels in the eastern regions of Turkey and the Syrian border area of migration.

In many studies maternal and obstetric differences between adolescent pregnancies and women of reproductive age have been compared, on the contrary in our study we aimed to compare immigrant Syrian adolescents with Turkish adolescents for the first time. We wanted to draw attention to the impact of immigration on adolescent pregnancy rates.

\section{METHODS}

A total of 22,724 deliveries at Osmaniye State Hospital between January 2013 and January 2020, including 15,883 Turkish and 6841 Syrian immigrants, were determined using the hospital records. Pregnancy and birth data of 868 Turkish adolescents and 522 Syrian adolescents, under 19 years old and who gave birth over 20 weeks, were analyzed retrospectively.

Maternal age, type of birth, birth weight, sex of the baby and fetal outcomes (live births and stillbirths) were recorded according to the data. Birth weight $<2500 \mathrm{gm}$ infants were considered low birth weight infants. Whether the differences between Turkish and Syrian adolescents were noteworthy (95\% confidence interval) was determined using the independent samples t test and Pearson Chi-Square test with statistical software Minitab (version 16.0, USA). $\mathrm{P}<0.05$ was considered statistically significant.

\section{RESULTS}

The number of Turkish adolescent pregnant women was $868(5.5 \%)$, the number of Syrian adolescent pregnant women was $522(7.6 \%)$ and the rate of Syrian adolescent pregnancy was higher.

Demographic data and obstetric outcomes of Turkish and Syrian adolescent pregnant were presented in Table 1. The mean ages of both groups were similar, 17.1 \pm 1.1 and $17 \pm 1.1$, respectively. There was no significant difference between neither birth weights nor low birth weight infant rates. Stillbirth rates were lower than live birth rates in both groups but higher in Syrian adolescents than Turkish adolescents. The sex of the infants in both groups was similar.

Vaginal delivery rates were higher than cesarean rates in both adolescent groups. The cesarean rate was observed $36.7 \%$ in Turkish adolescent pregnancies and $20.1 \%$ in Syrian adolescent pregnants, and the cesarean rate was significantly higher in Turkish adolescent pregnants $(\mathrm{p}<0.001)$. When the total of $1390(6.1 \%)$ adolescent pregnancies were evaluated, the cesarean rate was found to be $30.5 \%$, and the rate of low birth weight below 2500 gm was $11.1 \%$.

Table 1: Demographic data and obstetric outcomes of Turkish and Syrian adolescent pregnants.

\begin{tabular}{|c|c|c|c|c|c|}
\hline \multicolumn{2}{|l|}{ Characteristics } & $\begin{array}{l}\text { Turkish adolescents } \\
\mathrm{n}=\mathbf{8 6 8}\end{array}$ & $\begin{array}{l}\text { Syrian adolescents } \\
\mathrm{n}=522\end{array}$ & $\begin{array}{l}\text { Total } \\
n=1390\end{array}$ & P value \\
\hline \multicolumn{2}{|c|}{ Maternal age, years, mean \pm SD/min.-max. } & $17.1 \pm 1.1 / 12-18$ & $17 \pm 1.1 / 12-18$ & $17.1 \pm 1.1 / 12-18$ & 0.222 \\
\hline \multicolumn{2}{|c|}{ Birth weight, gm, mean \pm SD } & $3096 \pm 511$ & $3054 \pm 527$ & $3080 \pm 518$ & 0.137 \\
\hline \multirow{2}{*}{ Sex of newborn, n (\%) } & Female & $416(47.9)$ & $217(41.6)$ & $633(45.5)$ & \multirow{2}{*}{0.928} \\
\hline & Male & $452(52.1)$ & $305(58.4)$ & $757(54.5)$ & \\
\hline \multirow{2}{*}{ Type of birth, n (\%) } & Vaginal & $549(63.3)$ & $417(79.9)$ & $966(69.5)$ & \multirow{2}{*}{$<0.001$} \\
\hline & Cesarean & $319(36.7)$ & $105(20.1)$ & $424(30.5)$ & \\
\hline \multicolumn{2}{|c|}{ Stillbirth, n (\%) } & $2(0.2)$ & $5(1.0)$ & $7(0.5)$ & 0.312 \\
\hline \multicolumn{2}{|c|}{ Low birthweight (LBW, $\leq 2500$ gm), n (\%) } & $96(11.1)$ & $58(11.1)$ & $154(11.1)$ & 0.977 \\
\hline
\end{tabular}

Independent samples t test, Pearson Chi-Square test, SD.: Standard deviation, Min.: minimum, Max.: maximum

\section{DISCUSSION}

Although adolescent pregnancy is an increasing problem all over the world, especially in developing countries, the rate of adolescent pregnancy is higher. Adolescent pregnancies are generally evaluated in the high-risk pregnancy category due to poor socioeconomic status, maternal biological immaturity, and insufficient antenatal care which is a result of low education level. ${ }^{9,10}$ Although the prevalence of adolescent pregnancy is $4.6 \%$ in Turkey, it is observed to be increasing in Osmaniye with a $7.6 \%$ rate of immigrant adolescent pregnant, $5.5 \%$ rate of Turkish adolescent pregnant due to the effect of both being an eastern region and immigration camping area.

It is predicted that low birth weight infant prevalence is higher in adolescent pregnant and consequently neonatal 
and infant mortality rates are increased. ${ }^{11}$ Sekeroğlu et al reported $16.8 \%$, Malabarey et al reported about $15 \%$ rates of low birth weight in adolescent pregnancies and it was statistically significant for both studies. ${ }^{12,13}$ In our study, low birth weight infant rates were found $11.1 \%$ and equal in both adolescent pregnant groups. We attributed this situation to the increasingly improving conditions such as educational programs given to immigrant women at the hospital, and the availability of sufficient number of translators who could be reached and able to communicate with each patient, so physicians started to be able to follow up pregnancy on time, provide vitamin and iron support to immigrant pregnant. High rates of low birth weight in adolescent pregnancies are associated with irregular perinatal follow-up of the adolescent group, low educational level, biological and nutritional factors during pregnancy. ${ }^{14}$ In the current study, although the frequency of stillbirths is low in both groups, it was higher in Syrian adolescents than Turkish adolescents because of migration and war effects, language and cultural differences as well as the same adolescent pregnancies problems.

In adolescent pregnancies, fetal and maternal mortality increased because they gave birth at a very young age and possibly at short intervals. ${ }^{4}$ The most common causes of maternal mortality in adolescent pregnancies have been found as pregnancy-induced hypertension, puerperal sepsis, and septic abortion. ${ }^{15}$ We could not clearly evaluate obstetric complications of adolescent pregnancy in our study due to insufficient data, but no maternal mortality was observed in both groups. Prospective studies should be conducted to evaluate pregnancy complications and obstetric outcomes of immigrant adolescent pregnant.

Some studies have been suggested that adolescent pregnant have higher cesarean rates due to cephalopelvic disproportion because pelvic width and capacity do not yet have an adult shape. ${ }^{5,16}$ Psychological factors in adolescent pregnancies and high anxiety may also be other reasons for high adolescent cesarean rates. Women under the age of 18 have not completed the psychological development process and are not yet capable of having a baby. However, past studies have shown inconsistent data about cesarean rates in adolescent pregnancies and lower cesarean rates in adolescent pregnancies. ${ }^{2,4,17}$ In a study involving 40391 pregnants and evaluating cesarean delivery rates in adolescent pregnancies, Zeteroğlu et al concluded that biological immaturity is not an important factor affecting adolescent pregnancy results. ${ }^{18}$ In a study comparing obstetric outcomes of Turkish and Syrian pregnancies by Serin et al it was reported higher cesarean rates in Turkish pregnants than the Syrian pregnants, and the overall cesarean rate at $40 \%$, also it was observed the rate of normal vaginal delivery significantly higher in adolescent pregnancy. ${ }^{19}$ In our study, cesarean rates were lower $(30.5 \%)$ in adolescents than in the general population and normal vaginal delivery rates were higher in both groups. In addition, higher cesarean rate was observed in Turkish adolescent pregnant compared to Syrian adolescent pregnant. Due to financial opportunity in Turkish adolescents, they tend to give birth by cesarean section, which seems to be painless and short delivery method. Inalöz et al found a significantly lower cesarean rate in adolescent women (37.8\%) than nonadolescent women $(65.8 \%){ }^{20}$ Baş et al reported no differences between the rate of cesarean delivery among adolescent pregnancies and the rate of general cesarean delivery. ${ }^{21}$

As a result, adolescent pregnancies are slightly higher in Syrian pregnancies and poor obstetric outcomes are more common due to insufficient antenatal care and nutrition, negative effects of war, low socio-economic status, language, and cultural differences. The data was limited because of the large series of patients and inadequate enrollment due to the inability to communicate with Syrians.

\section{CONCLUSION}

Adolescent births carry maternal and neonatal risks. It is obvious that obstetric complications are high in adolescence, especially in early adolescents. Adolescent pregnancies should be followed closely as high-risk pregnancies considering their health and social consequences. Prevention of early marriages, which is an ongoing social tradition in our country, must be the first step in reducing adolescent pregnancies. Adolescent pregnancy frequency seems to be associated with low educational attainment. It will lead the specialized centers for adolescents to sex education, family planning counselling, antenatal care facilities to educate women in childbirth, and neonatal unit developed centers will play an important role to reduce these problems.

Funding: No funding sources

Conflict of interest: None declared

Ethical approval: The study was approved by the Institutional Ethics Committee Osmaniye state hospital

\section{REFERENCES}

1. Yoost JL, Hertweck SP, Barnett SN. The effect of an educational approach to pregnancy prevention among high-risk early and late adolescents. J Adolesc Health. 2014;55:222-7.

2. Rexhepi M, Besimi F, Rufati N, Alili A, Bajrami S, Ismaili H. Hospital-based study of maternal, perinatal and neonatal outcomes in adolescent pregnancy compared to adult women pregnancy. Open Access Maced J Med Sci. 2019;7(5):760.

3. Chandra-Mouli V, Camacho AV, Michaud PA. WHO guidelines on preventing early pregnancy and poor reproductive outcomes among adolescents in developing countries. J Adolesc Health. 2013;52(5):517-22.

4. Turkey Demographic and Health Survey 2013. Hacettepe University Institute of Population Studies. 
Ankara, Turkey; 2014. Available from: https://dhsprogram.com/pubs/pdf/FR352/FR352.pdf. Accessed on 23 September 2019.

5. Chandra PC, Schiavello HJ, Ravi B, Weinstein AG, Hook FB. Pregnancy outcomes in urban teenagers. Int J Gynaecol Obstet. 2002;79:117-22.

6. Stevens-Simon C, McAnarney ER. Adolescent pregnancy. Gestational weight gain and maternal and infant outcomes. Am J Dis Child. 1992;146:1359-64.

7. Hoekelman RA. Teenage pregnancy- one of our nation's most challenging dilemmas. Pediatr Ann. 1993;22:81-2.

8. Kost K, Maddow-Zimet I. U.S. Teenage Pregnancies, Births And Abortions, 2011: State Trends By Age, Race And Ethnicity. New York (NY): Guttmacher Institute; 2016.

9. Edirne T, Can M, Kolusari A, Yildizhan R, Adali E, Akdag B. Trends, characteristics, and outcomes of adolescent pregnancy in eastern Turkey. Int $\mathbf{J}$ Gynaecol Obstet. 2010;110:105-8.

10. İmir AG, Çetin M, Balta Ö, Büyükayhan D, Çetin A. Perinatal outcomes of adolescent pregnancies at a university hospital in Turkey. J Turkish-German Gynecol Assoc. 2008;9:71-4.

11. Aydin D. Adolescent pregnancy and adolescent motherhood. J Anatol Nurs Health Sci. 2013;16:4.

12. Malabarey OT, Balayla J, Klam SL, Shrim A, Abenhaim HA. Pregnancies in young adolescent mothers: a population-based study on 37 million births. J Pediatr Adolesc Gynecol. 2012;25:98-102.

13. Şekeroğlu M, Baksu A, İnce Z, Gültekin H, Göker $\mathrm{N}$, Özsoy S. Adolescent and old age pregnants obstetric results. Şişli Etfal Tıp Bülteni. 2009;43:1-7.

14. Gama SG, Szwarcwald CL, Leal Md M. Theme Filha MM: The pregnancy during adolescence as a risk factor for low birth weight, Brazil. Rev Saude Publica. 2001;35:74-80.
15. Hagues RJ, Bae D, Wickrama KK. Mediational pathways connecting secondary education and age at marriage to maternal mortality: A comparison between developing and developed countries. Wom Health. 2017;57(2):189-207.

16. Khwaja SS, Al-Sibai MH, Al-Suleiman SA, ElZibdeh MY. Obstetric implications of pregnancy in adolescence. Acta Obstet Gynecol Scand. 1986;65(1):57-61.

17. Ersoy GŞ, Kayar İ, Keser B, Ensari TA, Aytaç H, Çetin F. Obstetric outcomes of adolescent pregnancies in the Eastern Mediterranean region of Turkey. İstanbul Tıp Fakültesi Dergisi. 2015;78(4):97-101.

18. Zeteroglu S, Şahin I, Gol K. Cesarean delivery rates in adolescent pregnancy. Eur J Contracept Reprod Health Care. 2005;10:119-22.

19. Serin AN, Kayar I, Birge O, Çetin F, Seyhan Y. Syrian refugees maternal health and perinatal outcome in Turkey: a retrospective population-based study. J Gynaecol Wom Healthcare. 2019;2:105.

20. İnalöz EY, İngeç M, Yılmaz EP. Evaluation of the effects of adolescent pregnancies on maternal and perinatal outcomes in our region. Mustafa Kemal Üniv Tip Derg. 2017;8(30):6-14.

21. Baş EK, Bülbül A, Uslu S, Baş V, Elitok GK, Zubarioğlu U. Maternal characteristics and obstetric and neonatal outcomes of singleton pregnancies among adolescents. Med Sci Monit. 2020;26:e919922.

Cite this article as: Birge O, Serin AN, Kayar I. Prevalence and cesarean rates of immigrant adolescent pregnancies. Int J Reprod Contracept Obstet Gynecol 2021;10:1291-4. 